\title{
Fluoxetine inhibited extracellular matrix of pulmonary artery and inflammation of lungs in monocrotaline-treated rats
}

\author{
Xue-qin $\mathrm{LI}^{1,3}$, Han-ming WANG ${ }^{1}$, Chun-guang YANG ${ }^{1}$, Xin-hua ZHANG ${ }^{1}$, Dan-dan $\mathrm{HAN}^{1}$, Huai-liang WANG ${ }^{1,2, *}$ \\ ${ }^{1}$ Department of Clinical Pharmacology, College of Pharmacy and ${ }^{2}$ National Key Subject, Division of Respiratory Diseases, China \\ Medical University, Shenyang 110001, China; ${ }^{3}$ Department of Pharmacy, Zhongshan City People's Hospital, Zhongshan 528403, \\ China
}

\begin{abstract}
Aim: To investigate the effects of the selective serotonin reuptake inhibitor (SSRI) fluoxetine on extracellular matrix (ECM) remodeling of the pulmonary artery and inflammation of the lungs in pulmonary arterial hypertension (PAH) induced by monocrotaline in rats. Methods: MCT-induced chronic PAH was established in Wistar rats. After treatment with fluoxetine for 3 weeks, pulmonary hemodynamic measurement and morphological investigation of lung tissues were undertaken. The main components of the ECM, elastin and collagen, were detected using Van Gieson stain and Orcein stain, respectively, or using Victoria-ponceau's double stain. The ECM proteolytic enzymes matrix metalloproteinase (MMP)-2 and MMP-9, and the tissue inhibitors of metalloproteinase (TIMP)-1 and TIMP-2, were detected by Western blot. Inflammation of lung tissue was assayed using lung morphology and inflammatory cytokine expression. Results: Fluoxetine (2 and $10 \mathrm{mg} / \mathrm{kg}$ ) significantly inhibited MCT-induced PAH, attenuated pulmonary arterial muscularization and ECM remodeling, and decreased MMP/TIMP expression. Fluoxetine also suppressed inflammatory responses in lung tissue and inhibited the expression of the inflammatory cytokines interleukin-1 $\beta$ (IL-1 $\beta$ ), tumor necrosis factor- $\alpha$ (TNF- $\alpha$ ), monocyte chemotactic protein (MCP-1) and intercellular adhesion molecule-1 (ICAM-1).

Conclusion: Fluoxetine inhibited MCT-induced ECM remodeling of the pulmonary artery and inflammation of lung tissue. These effects were related to its inhibition on MMPs/TIMPs and cytokine productions.
\end{abstract}

Keywords: extracellular matrix; inflammation; pulmonary arterial hypertension; selective serotonin reuptake inhibitor

Acta Pharmacologica Sinica (2011) 32: 217-222; doi: 10.1038/aps.2010.187; published online 10 Jan 2011

\section{Introduction}

Pulmonary arterial hypertension $(\mathrm{PAH})$ is characterized by a sustained and progressive increase in pulmonary arterial pressure (PAP) with pathological changes involving vasoconstriction, vascular remodeling and inflammation, which may lead to right-heart failure and ultimately death. Whereas the pathogenesis of PAH is complicated, it is believed that the main processes lead to progressive pulmonary arterial remodeling, including hypertrophy and hyperplasia of pulmonary arterial smooth muscle cells (PASMCs), muscularization of normally nonmuscular peripheral arteries, and deposition of the extracellular matrix $(\mathrm{ECM})^{[1-3]}$.

The ECM, as a biologically active and dynamic composition of vasculature, plays important roles in maintaining the histological structure of the vessel wall and regulating PASMCs

\footnotetext{
* To whom correspondence should be addressed.

E-mail hlwang@mail.cmu.edu.cn

Received 2010-05-30 Accepted 2010-09-29
}

contractility and proliferation ${ }^{[4]}$. Collagen and elastin are the major structural components of the ECM, which interlace in a complex network and are well adapted to accomplish mechanical tasks ${ }^{[5,6]}$. The ECM is regulated by specific and unique proteolytic enzymes, the matrix metalloproteinases (MMPs). Among the MMPs, MMP-2, and MMP-9 degrade collagen more efficiently than the others, and they are involved in the vascular smooth muscle cell activation and neointimal formation that characterize arterial tissue remodeling after injury ${ }^{[7,8]}$. MMPs are modulated by the tissue inhibitors of metalloproteinase (TIMP)-1 and TIMP-2. The imbalance of MMPs/TIMPs induces matrix abnormality and remodeling, which has been found in idiopathic PAH patients ${ }^{[9]}$. Thus, the integrity and balance of ECM is essential for normal lung function and response to injury ${ }^{[10]}$, and identifying MMP/TIMP changes will help us better understand the pathobiology of $\mathrm{PAH}$.

Serotonin, as a type of vasoconstrictor and mitogen for smooth muscle cells, is an important endogenous vasoactive substance involved in PAH. The internalization of 
serotonin into PASMCs by high-affinity serotonin transporters (SERT) promoted smooth muscle cell hyperplasia and hypertrophy ${ }^{[11,12]}$. It was reported that the plasma concentration in serotonin was significantly increased in PAH patients ${ }^{[13]}$. We have previously reported that serotonin induced PASMCs mitogenesis in vitro, and serotonin selective reuptake inhibitor (SSRI) fluoxetine inhibited serotonininduced PASMCs proliferation via blocking SERT ${ }^{[14]}$. We have also found that SSRI fluoxetine and sertraline protected against pulmonary vascular remodeling by inhibiting pulmonary vascular muscularization in monocrotaline (MCT)induced pulmonary hypertensive rats ${ }^{[15,16]}$. However, whether SSRI has a protective effect against ECM remodeling in the pulmonary artery remains unknown.

Inflammatory mechanisms play an important role in the development of PAH. It has been demonstrated that lymphocytes and macrophages were present in the vicinity of remodeled pulmonary vessels and that cytokines such as interleukin (IL)-1, IL-6, IL-8, tumor necrosis factor-a (TNF-a), monocyte chemotactic protein-1 (MCP-1) and intercellular adhesion molecule-1 (ICAM-1) were increased in PAH patients ${ }^{[17-20]}$. We have also reported previously that chronic lung inflammation existed in MCT-induced PAH rats ${ }^{[21]}$. However, several studies have shown that fluoxetine had an anti-inflammatory effect by decreasing cytokine production from peripheral blood in patients suffering from major depressive disorder ${ }^{[22]}$ and by attenuating carrageenan-induced inflammation response in $\operatorname{rats}^{[23]}$. Yet, whether fluoxetine inhibits an inflammatory response in $\mathrm{PAH}$ is not clear.

Therefore, the present study is to investigate the effects of fluoxetine on the extracellular matrix of the pulmonary artery and on the inflammation of lung tissue in MCT-induced PAH rats.

\section{Materials and methods}

\section{Animal models}

Male Wistar rats $(167 \pm 18$ g) from Animal Resource Center, China Medical University (Certification No: Liaoning 034) were divided into four groups, ie, control, MCT, MCT plus fluoxetine $2 \mathrm{mg} \cdot \mathrm{kg}^{-1} \cdot \mathrm{d}^{-1}(\mathrm{MCT}+\mathrm{F} 2)$ and MCT plus fluoxetine $10 \mathrm{mg} \cdot \mathrm{kg}^{-1} \cdot \mathrm{d}^{-1}(\mathrm{MCT}+\mathrm{F} 10)$. Rats in the $\mathrm{MCT}, \mathrm{MCT}+\mathrm{F} 2$, and $\mathrm{MCT}+\mathrm{F} 10$ groups were treated with a single intraperitoneal injection of $60 \mathrm{mg} / \mathrm{kg} \mathrm{MCT} \mathrm{(Sigma,} \mathrm{St} \mathrm{Louis,} \mathrm{USA),} \mathrm{and} \mathrm{rats}$ in the control group were treated with an equivalent amount of vehicle. Rats in the MCT+F2 and MCT+F10 groups also received fluoxetine (Eli Lilly, Indianapolis, USA) at doses of 2 $\mathrm{mg} \cdot \mathrm{kg}^{-1} \cdot \mathrm{d}^{-1}$ and $10 \mathrm{mg} \cdot \mathrm{kg}^{-1} \cdot \mathrm{d}^{-1}$ by gavage, respectively. Meanwhile, rats in the control and MCT groups received vehicle only. Rats were fed with solid food and water ad lib in an alternating $12 \mathrm{~h}$ light/dark cycle under controlled temperature $\left(18-22^{\circ} \mathrm{C}\right)$ and humidity $(50 \%-65 \%)$ for 3 weeks.

\section{Hemodynamic measurement}

After 3 weeks, rats were anaesthetized with 3\% sodium pentobarbital $(40 \mathrm{mg} / \mathrm{kg})$. A polyethylene catheter (PE-50) was inserted into the right carotid artery to measure systemic arte- rial pressure (SAP). A PV-1 catheter was inserted into the pulmonary artery through the right jugular vein via the right atrium and ventricle for measurement of pulmonary arterial pressure (PAP). Hemodynamic variables were measured with a pressure transducer and recorded on a polygraph system (RM6000, Kohden, Tokyo, Japan).

\section{Lung morphology}

The lower lobe of right lungs and pulmonary arteries were fixed with formalin solution. After paraffin embedding, $5 \mu \mathrm{m}$ sections were stained with hematoxylin and eosin for investigation of inflammation and the thickness of the pulmonary arterial wall by light microscopy. The external and internal diameters of 7-10 intra-acinar pulmonary arteries per rat were measured in 5 rats of each group. The ratio of the medial thickness of the pulmonary artery was calculated by the equa-

The thickness of pulmonary arterial wall=

$$
\frac{\text { External diameter-internal diameter }}{\text { External diameter }} \times 100 \%
$$

tion shown as follows ${ }^{[24]}$ :

\section{Collagen and elastin staining}

Serial paraffin sections were stained with Van Gieson stain, Orcein stain, or Victoria-ponceau's double stain to localize collagen and elastin in lungs and pulmonary arteries.

\section{Western blot}

The left lungs were immediately removed to liquid nitrogen for measurement of protein expression. Lung samples were homogenized in lysis buffer. Total protein from each sample was separated by sodium dodecyl sulfate polyacrylamide gel electrophoresis and transferred to nitrocellulose membrane. The membranes were blocked by TBS- $0.05 \%$ Tween-20 (TBS-T) with $5 \%$ nonfat dry milk for $60 \mathrm{~min}$ and were then incubated with mouse anti-rat MMP-2 (1:600, Santa Cruz, California, USA) and TIMP-2 (1:400, Santa Cruz, California, USA); goat anti-rat MMP-9 (1:600, Santa Cruz, California, USA), TIMP-1 (1:400, Santa Cruz, California, USA) and TNF-a (1:1000, Santa Cruz, California, USA); rabbit anti-rat IL-1 $\beta$ (1:400, USCN, Missouri, USA), ICAM-1 (1:800, Santa Cruz, California, USA), MCP-1 (1:400, Boster, Wuhan, China) and $\beta$-actin (1:2000, Santa Cruz, California, USA) antibodies in TBS-T with 5\% BSA overnight at $4{ }^{\circ} \mathrm{C}$, respectively. After a corresponding secondary antibody treatment, the membranes were exposed to a mixture of enhanced chemiluminescence reagent (Applygen Technologies Inc., Beijing, China), and the resulting chemiluminescent reaction was detected by Fuji X-ray film. Then the film was scanned, and the intensity of immunoblot bands was quantified by densitometry using imaging software.

\section{Statistical methods}

All data are expressed as the mean $\pm S D$. Statistical comparisons were made by one-way analysis of variance, and statistical differences between two groups were established using the least significant difference test. 


\section{Results}

Effect of fluoxetine on hemodynamics and the thickness of the pulmonary arterial wall

The mean PAP was elevated in the MCT group compared with the control group $(P<0.01)$. Mean PAPs in the MCT+F2 and $\mathrm{MCT}+\mathrm{F} 10$ groups were both decreased significantly $(P<0.05$, vs MCT). However, the SAPs in the four groups were not significantly different. The muscularization of lung tissue from the right lower lobe was investigated under light microscope. The thickness of pulmonary arterial walls in the MCT group was increased $(P<0.01$ vs control). Also, fluoxetine decreased the thickness ratio in the MCT+F2 and MCT+F10 groups compared with the MCT group in a dose-related manner $(P<0.01$, Table 1).

\section{Evaluation of elastin and collagen}

Figure 1A shows collagen staining of lung tissue, and demonstrates that collagen in the MCT group was significantly increased and was diffused all around the lungs and pulmonary arterioles; fluoxetine markedly decreased collagen deposition and ameliorated structural destruction of lungs in a dose-related manner. Figure 1B shows elastin staining of the main pulmonary arteries and demonstrates that the elastic fibers in the MCT group were significantly increased and disrupted; fluoxetine at doses of $10 \mathrm{mg} / \mathrm{kg}$ decreased elastic fiber hyperplasia and kept the integrity of the arterial structure. Similar results were also found in Figure 1C and 1D indicating that fluoxetine markedly decreased remodeling and destruction of elastin and collagen induced by MCT treatment.

\section{B}
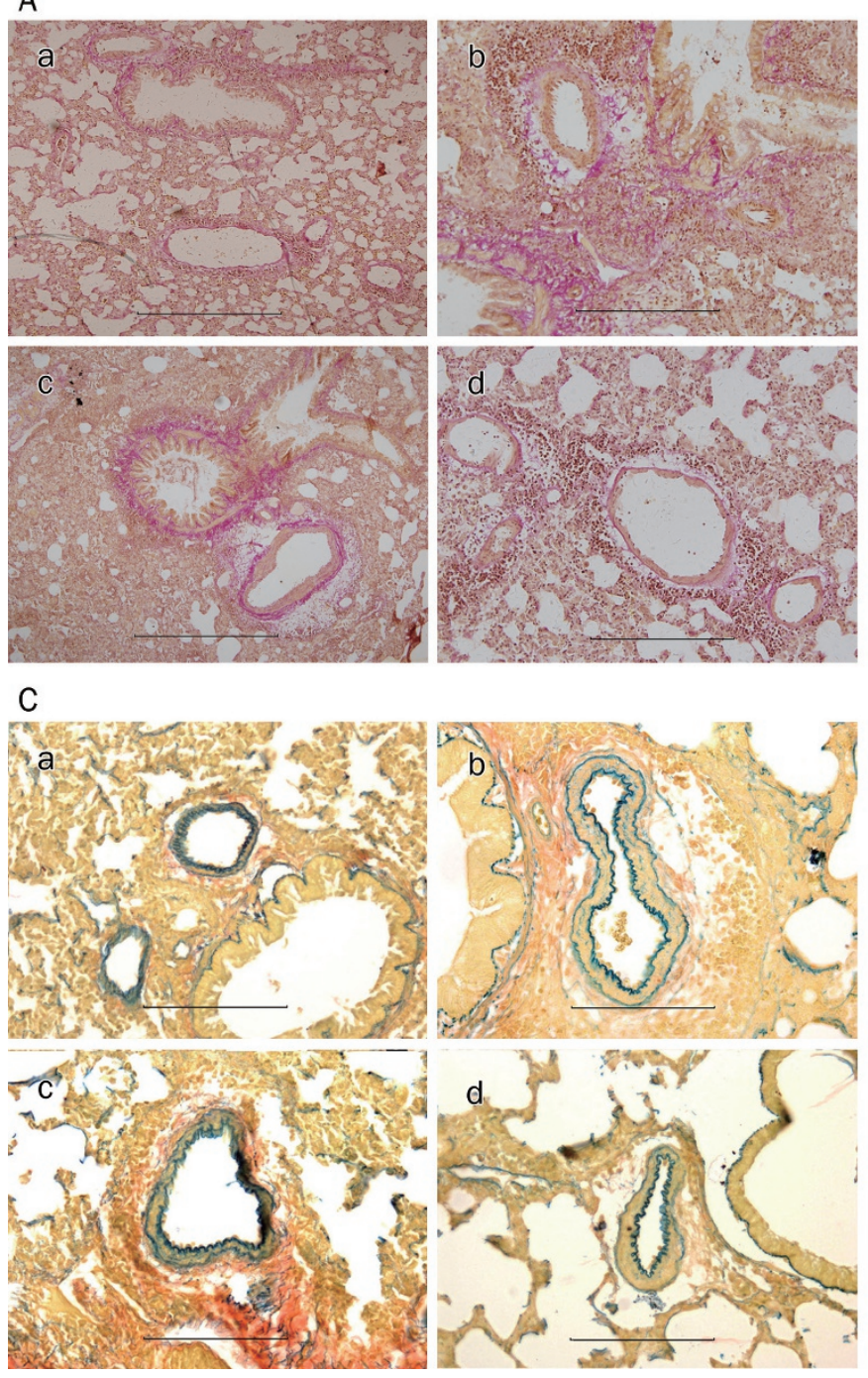
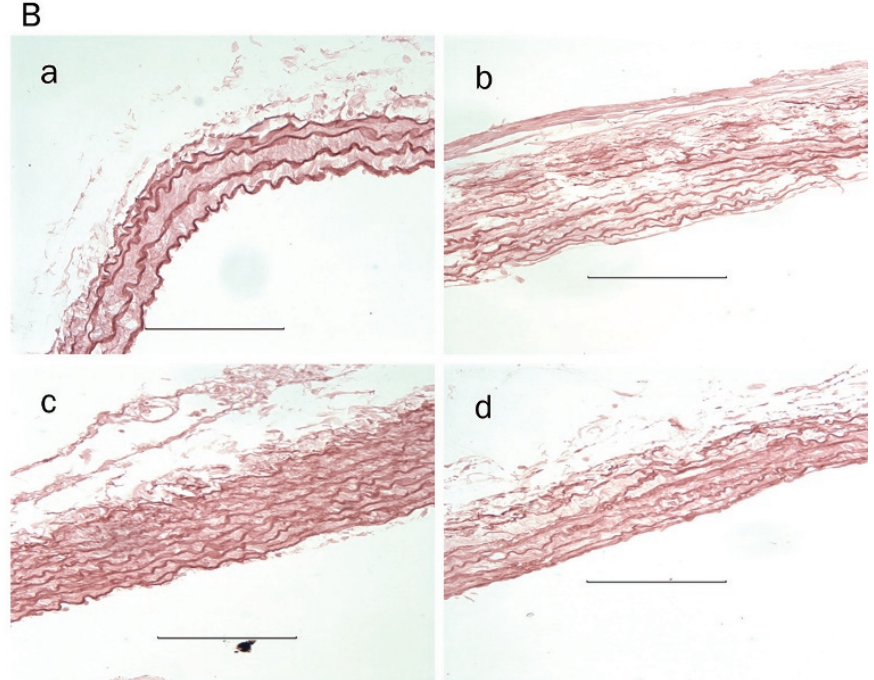

D
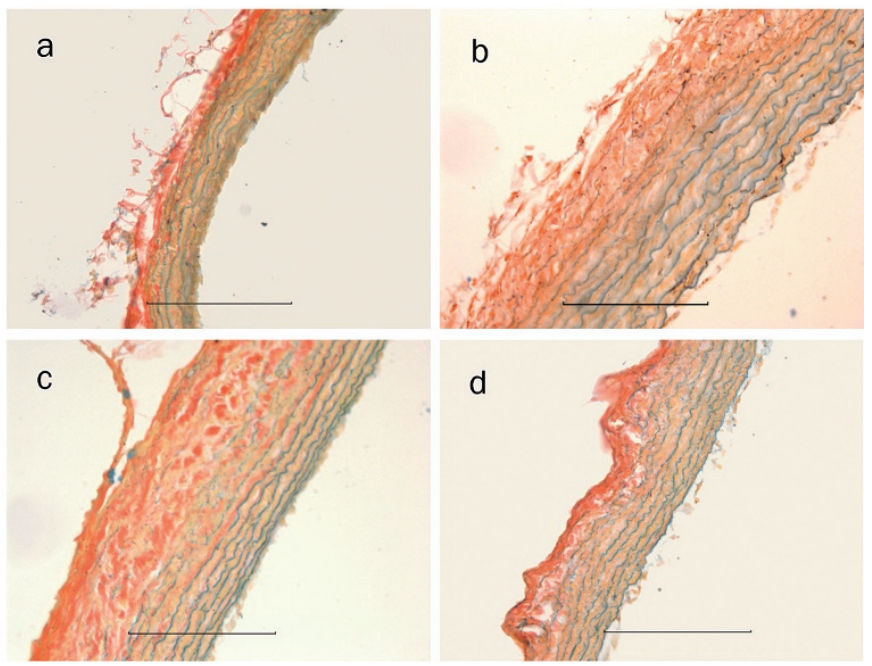

Figure 1. Comparison of elastin and collagen deposition in different groups. (A) collagen deposition (staining red) in lungs. a, b, c, and d represent control, MCT, MCT+F2, and MCT+F10 group, respectively (bars, $100 \mu \mathrm{m}$ ). (B) elastin in main pulmonary arteries. a, b, c, and d represent control, MCT, $\mathrm{MCT}+\mathrm{F} 2$, and MCT+F10 group, respectively (bars, $100 \mu \mathrm{m}$ ). (C) Double staining in elastin and collagen in lungs. a, b, c and d represent elastin(staining bluish green) and collagen (staining red) in control, MCT, MCT+F2, and MCT+F10 group, respectively (bars, $100 \mu \mathrm{m}$ ). (D) Double staining in elastin and collagen in main pulmonary arteries. a, b, c, and d represent elastin (staining bluish green) and collagen (staining red) in control, MCT, MCT+F2, and MCT+F10 group (bars, $100 \mu \mathrm{m})$. 
Table 1. Comparison of hemodynamic measurement and the thickness of pulmonary arteries in different groups. Data were expressed as mean \pm SD. ${ }^{\mathrm{c}} P<0.01$ vs control. ${ }^{\mathrm{e}} \mathrm{P}<0.05,{ }^{\mathrm{f}} P<0.01$ vs MCT group.

\begin{tabular}{|c|c|c|c|c|}
\hline & Control $(n=15)$ & $\operatorname{MCT}(n=10)$ & $\mathrm{MCT}+\mathrm{F} 2(n=9)$ & $\mathrm{MCT}+\mathrm{F} 10(n=9)$ \\
\hline Body weight (g) & $260 \pm 21$ & $236 \pm 29$ & $226 \pm 36$ & $241 \pm 20$ \\
\hline $\operatorname{PAP}(\mathrm{mmHg})$ & $17.4 \pm 1.7$ & $29.8 \pm 7.5^{c}$ & $26.9 \pm 5.7^{e}$ & $24.5 \pm 3.3^{\mathrm{e}}$ \\
\hline Ratio of medial thickness of pulmonary artery (\%) & $36.1 \pm 10.3$ & $53.5 \pm 8.8^{c}$ & $44.7 \pm 9.7^{f}$ & $38.5 \pm 10.1^{f}$ \\
\hline
\end{tabular}

\section{Evaluation of lung inflammation}

As shown in Figure 2, marked perivascular and peribronchiolar inflammatory cell infiltration and angiogenesis of lung tissues were found in the MCT group. Fluoxetine predominantly attenuated MCT-induced inflammation and angiogenesis of lung tissues.

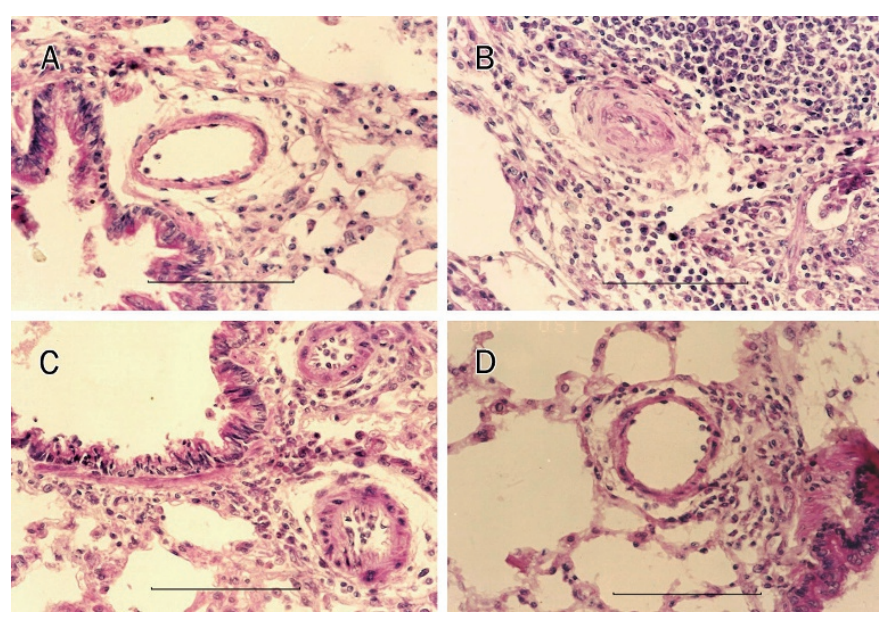

Figure 2. Comparison of lung inflammatory changes illustrated by representative photomicrographs. $\mathrm{A}, \mathrm{B}, \mathrm{C}$, and $\mathrm{D}$ represent control, $\mathrm{MCT}$, $\mathrm{MCT}+\mathrm{F} 2$, and MCT+F10 group, respectively (bars, $100 \mu \mathrm{m}$ ).

\section{MMP-2, MMP-9, TIMP-1, and TIMP-2 protein expressions}

As shown in Figure 3, the levels of MMP-2, MMP-9, TIMP1 , and TIMP-2 in the MCT group were significantly increased compared with control. Fluoxetine inhibited MCT-induced increase of MMPs and TIMPs in a dose-dependent manner.

\section{Inflammatory cytokine IL-1 $\beta$, TNF- $\alpha$, MCP-1, and ICAM-1 expres-} sions

Compared with the control group, the levels of IL-1 $\beta$, TNF- $\alpha$, MCP-1, and ICAM-1 in the MCT group were significantly increased from $0.74 \pm 0.19,0.58 \pm 0.24,0.64 \pm 0.11$, and $0.91 \pm 0.11$ to $1.16 \pm 0.22,1.00 \pm 0.22,0.92 \pm 0.12$, and $1.04 \pm 0.08$, respectively. Fluoxetine inhibited MCT-induced increase of these cytokines in a dose dependent manner (Figure 4).

\section{Discussion}

The present study shows that MCT-induced PAH is accom-
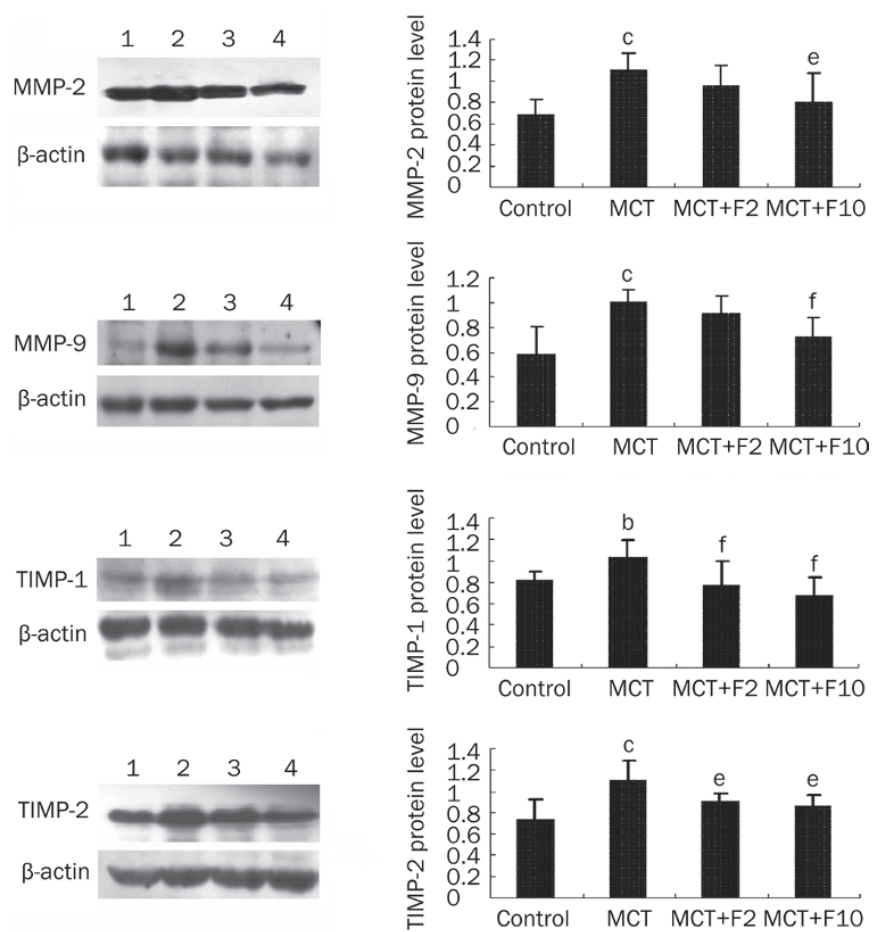

Figure 3. Comparison of MMP-2, MMP-9, TIMP-1, and TIMP-2 protein expression in lungs from different groups $1,2,3$, and 4 represent control, $\mathrm{MCT}, \mathrm{MCT}+\mathrm{F} 2$, and $\mathrm{MCT}+\mathrm{F} 10$ group, respectively. Data expressed as mean \pm SD $(n=4) .{ }^{\mathrm{b}} P<0.05,{ }^{\mathrm{c}} P<0.01$ compared with control. ${ }^{\mathrm{e}} P<0.05$, ${ }^{f} P<0.01$ compared with MCT.

panied by an ECM remodeling of pulmonary arteries and an inflammatory response of lung tissue, in which there are marked fragmentation and reconstruction of elastin and collagen, increased expression of MMP-2, 9 and TIMP-1, 2, and increased expression of inflammatory cytokines. ECM remodeling, as an important change in pulmonary arterial reconstruction, results from a complex interplay between synthesis and proteolysis of ECM constituents. Early clinical studies have shown that fragmentation of the internal elastic lamina and an increase of active MMPs exist in the pulmonary arteries of $\mathrm{PAH}$ patients ${ }^{[9]}$. In animal PAH models, the progression of hypoxia-induced PAH is associated with a time-dependent increase in MMP activity that is mainly related to an increase of MMP- $2^{[8]}$. Higher expressions of MMP-2, 9, TIMP-1 mRNA, and enzymatic activity of MMP-2, 9 in lungs were also found 

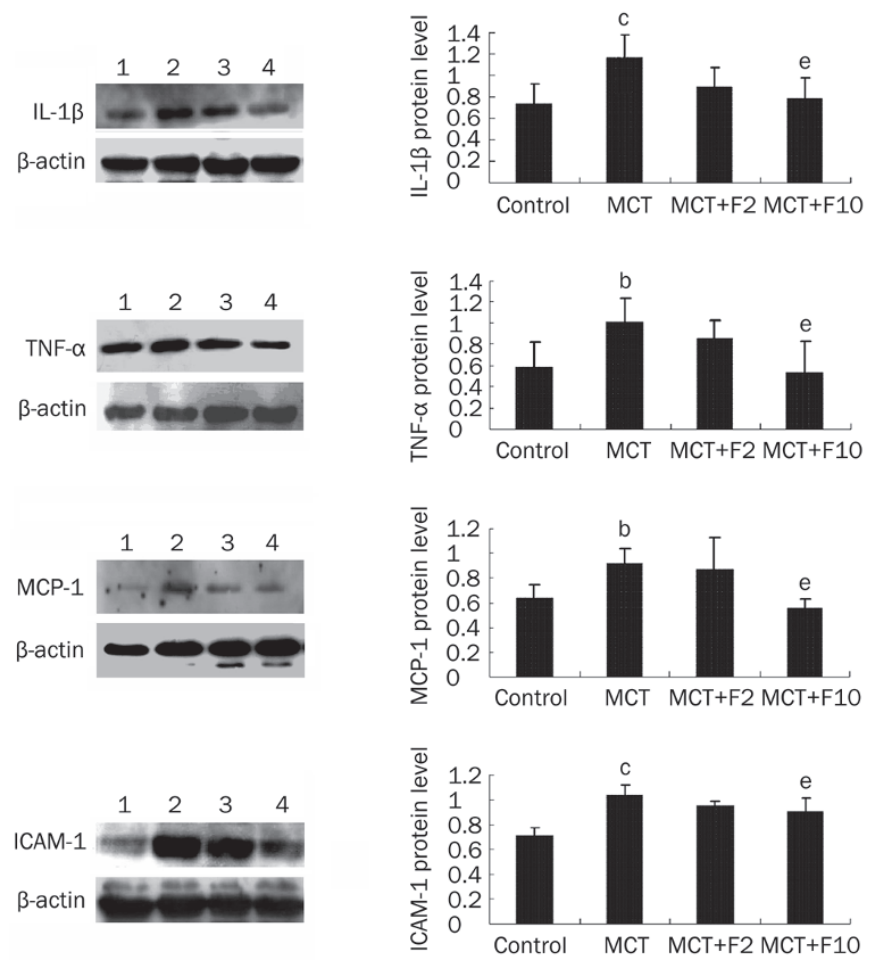

Figure 4. IL-1 $\beta$, TNF- $\alpha$, MCP-1, and ICAM-1 protein expression in lung tissues from different groups by Western blot. 1, 2, 3, and 4 represent control, MCT, MCT+F2, and MCT+F10 group, respectively. Data expressed as mean \pm SD $(n=4)$. ${ }^{\mathrm{b}} P<0.05,{ }^{\mathrm{c}} P<0.01$ compared with control. ${ }^{\mathrm{e}} P<0.05$, ${ }^{\mathrm{f}} P<0.01$ compared with MCT.

in MCT-induced PAH rats ${ }^{[25]}$. It is thought that injection of MCT causes endothelial cell injury in pulmonary arteries and inflammatory response in lungs ${ }^{[21]}$ and induces MMPs to be secreted from injured endothelial cells and inflammatory cells (such as mast cells, monocytes, macrophages) ${ }^{[26,27]}$. The activation of MMPs initiates ECM degradation, and TIMPs expression is augmented for keeping a dynamic balance between ECM construction and destruction. The above mentioned evidence indicates that the present findings, in which MCT induced increases of MMP-2, 9/TIMP-1, 2 in lungs, are in accordance with the results from previous studies.

In the present study, fluoxetine markedly inhibits MCTinduced pulmonary arterial hypertension and attenuated pulmonary artery muscularization, as we have reported previously $^{[15]}$. Furthermore, we also found that fluoxetine reduced the elastin and collagen deposition and destruction in pulmonary arteries induced by MCT, in which MMP-2, 9/ TIMP-1, 2 expressions are obviously suppressed. It is known that serotonin is involved in the pathophysiology of lung fibrosis via increasing proliferation and collagen synthesis by fibroblasts ${ }^{[28]}$ and that it has reciprocal effects on collagens and collagenase (a type of MMP) ${ }^{[29]}$. Shum JK et al reported that serotonin induces MMP production via phospholipase $\mathrm{C}$, protein kinase $C$, and extracellular signal-regulated kinase (ERK) $1 / 2$ pathway in smooth muscle cells ${ }^{[30]}$. Our previous study showed that the serotonin-induced mitogenesis of PASMCs is mediated by SERT, in which the signal transduction for serotonin is dependent on the ERK1/2 pathway ${ }^{[14]}$. Benekareddy et al also reported that fluoxetine regulates MMP-2/ MMP-9 and TIMP1-4 in the adult rat hippocampus ${ }^{[31]}$. Taken this information and the present results together, we believe that fluoxetine-induced regulation of MMP-2, 9/TIMP-1, 2 is closely related to the inhibition of ECM remodeling, in which the serotonin intracellular signal pathway might be involved. In the fluoxetine group, we found that both MMP and TIMP expressions were inhibited. It is known that regulation of MMP expression also affects TIMP expression, and therefore a delicate balance exists between MMP activation and inhibition by TIMPs ${ }^{[32]}$. It is thought that a reduction of TIMP expression is related to the inhibition of MMPs expression and ECM remodeling by fluoxetine.

We have also shown how fluoxetine remarkably inhibits MCT-induced pulmonary inflammation and how this inhibition is accompanied by the decreased expression of inflammatory cytokines. Some studies report that serotonin is closely linked to inflammatory responses, including the induction of mast cell adhesion and migration, activation of alveolar macrophages, and development and maintenance of arterial remodeling through the release of cytokines ${ }^{[33-35]}$. It is found that fluoxetine has anti-inflammatory properties and that there is a positive correlation between SERT and cytokine mRNA expression in patients with depression, who are affected by chronic treatment with fluoxetine ${ }^{[22]}$. Also, the present study found that fluoxetine suppressed inflammatory responses in MCT-induced PAH rats, in which inhibition of inflammatory cytokines is involved. Thus, it is thought that the serotonergic system is likely to be involved in the modulation of peripheral inflammation, and SSRIs may play an important role in working against the inflammatory response in PAH. It is known that MMPs act broadly in physiological and pathological inflammatory processes via regulating inflammatory cytokines activity $^{[7]}$. MMPs are regulated by many cytokines, notably TNF- $\alpha$ and IL-1 $\beta$, that induce MMP activity markedly and increase their mRNA levels via action through the promoter region of MMP genes ${ }^{[36]}$. Kubera et al also reported that the anti-inflammatory effects of fluoxetine developed through suppression of the interferon-gamma/interlenkin-10 production ratio in the central nervous system ${ }^{[37]}$. Therefore, there is a complex interaction between MMPs and inflammatory response which might be involved in the mechanism of fluoxetine protection against PAH.

In conclusion, fluoxetine inhibited MCT-induced ECM remodeling of pulmonary artery and inflammation of lungs, effects which were related to its inhibition on MMPs/TIMPs and cytokine productions.

\section{Acknowledgements}

Projects supported by National Natural Science Foundation of China (№ 30973533 and № 30572194 ).

\section{Author contribution}

Xue-qin LI and Huai-liang WANG designed the research and 
wrote the paper. Xue-qin LI, Han-ming WANG, Chun-guang YANG, and Dan-dan HAN performed the research. Xin-hua ZHANG offered technical assistance.

\section{References}

1 Morrell NW, Adnot S, Archer SL, Dupuis J, Jones PL, MacLean MR, et al. Cellular and molecular basis of pulmonary arterial hypertension. J Am Coll Cardiol 2009; 54: S20-31.

2 Tuder RM. Pathology of pulmonary arterial hypertension. Semin Respir Crit Care Med 2009; 30: 376-85.

3 Raiesdana A, Loscalzo J. Pulmonary arterial hypertension. Ann Med 2006; 38: 95-110.

4 Eble JA, Niland S. The extracellular matrix of blood vessels. Curr Pharm Des 2009; 15: 1385-400.

5 Lammers SR, Kao PH, Qi HJ, Hunter K, Lanning C, Albietz J, et al. Changes in the structure-function relationship of elastin and its impact on the proximal pulmonary arterial mechanics of hypertensive calves. Am J Physiol Heart Circ Physiol 2008; 295: H1451-9.

6 Frisdal E, Gest V, Vieillard-Baron A, Levame M, Lepetit H, Eddahibi S, et al. Gelatinase expression in pulmonary arteries during experimental pulmonary hypertension. Eur Respir J 2001; 18: 838-45.

7 Ambalavanan N, Nicola T, Li P, Bulger A, Murphy-Ullrich J, Oparil S, et al. Role of matrix metalloproteinase-2 in newborn mouse lungs under hypoxic conditions. Pediatr Res 2008; 63: 26-32.

8 Novotná J, Herget J. Possible role of matrix metalloproteinases in reconstruction of peripheral pulmonary arteries induced by hypoxia. Physiol Res 2002; 51: 323-34.

9 Lepetit H, Eddahibi S, Fadel E, Frisdal E, Munaut C, Noel A, et al. Smooth muscle cell matrix metalloproteinases in idiopathic pulmonary arterial hypertension. Eur Respir J 2005; 25: 834-42.

10 Aytekin M, Comhair SA, de la Motte C, Bandyopadhyay SK, Farver CF, Hascall VC, et al. High levels of hyaluronan in idiopathic pulmonary arterial hypertension. Am J Physiol Lung Cell Mol Physiol 2008; 295 : L789-99.

11 MacLean MR, Dempsie Y. Serotonin and pulmonary hypertension from bench to bedside? Curr Opin Pharmacol 2009; 9: 281-6.

12 MacLean MR, Dempsie Y. The serotonin hypothesis of pulmonary hypertension revisited. Adv Exp Med Biol 2010; 661: 309-22.

13 Kéreveur A, Callebert J, Humbert M, Hervé P, Simonneau G, Launay $\mathrm{JM}$, et al. High plasma serotonin levels in primary pulmonary hypertension: effect of long-term epoprostenol (prostacyclin) therapy. Arterioscler Thromb Vasc Biol 2000; 20: 2233-9.

14 Song D, Wang HL, Wang S, Zhang XH. 5-Hydroxytryptamine-induced proliferation of pulmonary artery smooth muscle cells are extracellular signal-regulated kinase pathway dependent. Acta Pharmacol Sin 2005; 26: 563-7.

15 Li XQ, Hong Y, Wang Y, Zhang XH, Wang HL. Sertraline protects against monocrotaline-induced pulmonary hypertension in rats. Clin Exp Pharmacol Physiol 2006; 33: 1047-51.

16 Zhai FG, Zhang XH, Wang HL. Fluoxetine protects against monocrotaline-induced pulmonary arterial hypertension: potential roles of induction of apoptosis and upregulation of Kv1.5 channels in rats. Clin Exp Pharmacol Physiol 2009; 36: 850-6.

17 Dorfmüller $\mathrm{P}$, Perros F, Balabanian K, Humber M. Inflammation in pulmonary arterial hypertension. Eur Respir J 2003; 22: 358-63.

18 Mathew R. Inflammation and pulmonary hypertension. Cardiol Rev 2010; 18: 67-72.

19 Chaouat A, Savale L, Chouaid C, Tu L, Sztrymf B, Canuet M, et al. Role for interleukin-6 in COPD-related pulmonary hypertension. Chest 2009; 136: 678-87.

20 Hassoun PM, Mouthon L, Barberà JA, Eddahibi S, Flores SC,
Grimminger F, et al. Inflammation, growth factors, and pulmonary vascular remodeling. J Am Coll Cardiol 2009; 54: S10-9.

21 Wang HL. The serotonin receptor and transporter are potential therapeutic targets for pulmonary hypertension. Curr Opin Investig Drugs 2004; 5: 963-6.

22 Tsao CW, Lin YS, Chen CC, Bai CH, Wu SR. Cytokines and serotonin transporter in patients with major depression. Prog Neruopsychopharmacol Biol Psychiatry 2006; 30: 899-905.

23 Abdel-Salam OM, Baiuomy AR, Arbid MS. Studies on the antiinflammatory effect of fluoxetine in rat. Pharmacol Res 2004; 49: 119-31.

24 Guignabert C, Raffestin B, Benferhat R, Raoul W, Zadigue P, Rideau $D$, et al. Serotonin transporter inhibition prevents and reversers monocrotaline-induced pulmonary hypertension in rats. Circulation 2005; 111: 2812-9.

25 Wang XM, Zhou TF, Liu B, Wei L, Shi K, Zhao SS, et al. Changes of MMP-2,9 and TIMP-1 expressions in rats with pulmonary arterial hypertension after captopril and losartan interventions. Sichuan Da Xue Xue Bao Yi Xue Ban 2009; 40: 255-9.

26 Tozzi CA, Thakker-Varia S, Yu SY, Bannett RF, Peng BW, Poiani GJ, et al. Mast cell collagenase correlateds with regression of pulmonary vascular remodeling in the rat. Am J Respir Cell Mol Biol 1998; 18: 497-510.

27 Emonard H, Grimoud JA. Matrix metalloproteinases. Cell Mol Biol 1990; 36: 131-53.

28 Fabre A, Marchal-Sommé J, Marchand-Adam S, Quesnel C, Borie R, Dehoux $\mathrm{M}$, et al. Modulation of bleomycin-induced lung fibrosis by serotonin receptor antagonists in mice. Eur Respir J 2008; 32: 42636.

29 Passaretti TV, Wilcox BD, Jeffrey JJ. Serotonin regulation of gene expression in uterine extracellular matrix: reciprocal effects on collagens and collagenase. Mol Cell Endocrinol 1996; 120: 125-32.

30 Shum JK, Melendez JA, Jeffrey JJ. Serotonin-induced MMP-13 production is mediated via phospholipase $\mathrm{C}$, protein kinase C, and ERK1/2 in rat uterine smooth muscle cells. J Biol Chem 2002; 277: 4283040.

31 Benekareddy M, Mehrotra P, Kulkarni VA, Ramakrishnan P, Dias $B G$, Vaidya VA. Antidepressant treatments regulate matrix metalloproteinases-2 and -9 (MMP-2/MMP-9) and tissue inhibitors of the metalloproteinases (TIMPS 1-4) in the adult rat hippocampus. Synapse 2008; 62: 590-600.

32 Keller KE, Aga M, Bradley JM, Kelley MJ, Acott TS. Extracellular matrix turnover and outflow resistance. Exp Eye Res 2009; 88: 676-82.

33 Kushnir-Sukhov NM, Gilfillan AM, Coleman JW, Brown JM, Bruening S, Toth $\mathrm{M}$, et al. 5-hydroxytryptamine induces mast cell adhesion and migration. J Immunol 2006; 177: 6422-32.

34 Mikulski Z, Zaslona Z, Cakarova L, Hartmann P, Wilhelm J, Tecott $\mathrm{LH}$, et al. Serotonin activates murine alveolar macrophages through 5-HT2C receptors. Am J Physiol Lung Cell Mol Physiol 2010; 299: L272-80.

35 Lima C, Souza VM, Soares AL, Macedo MS, Tavares-de-Lima W, Vargaftig BB. Interference of methysergide, a specific 5-hydroxytryptamine receptor antagonist, with airway chronic allergic inflammation and remodeling in a murine model of asthma. Clin Exp Allergy 2007; 37: 723-34.

36 Manicone AM, McGuire JK. Matrix metalloproteinases as modulators of inflammation. Cell Dev Biol 2008; 19: 34-41.

37 Kubera M, Lin AH, Kenis G, Bosmans E, van Bockstaele D, Maes M. Anti-inflammatory effects of antidepressants through suppression of the interferon-gamma/interleukin-10 production ratio. J Clin Psychopharmacol 2001; 21: 199-206. 